\title{
Liste des rapporteurs et rapportrices 2018-2019
}

\section{(2) OpenEdition}

1 Journals

Édition électronique

URL : https://journals.openedition.org/travailemploi/9989

DOI : 10.4000/travailemploi.9989

ISSN : 1775-416X

\section{Éditeur}

DARES - Ministère du Travail

\section{Édition imprimée}

Date de publication : 1 mars 2020

Pagination : 135

ISSN : 0224-4365

\section{Référence électronique}




\section{LISTE DES RAPPORTEURS \\ ET RAPPORTRICES \\ 2018-2019}

Le comité de rédaction de Travail et Emploi remercie chaleureusement les rapporteurs et les rapportrices qui ont contribué à l'évaluation des projets

d'articles soumis en 2018 et en 2019

Félicien ACCROMBESSY
Philippe ADAIR
Tania ANGELOFF
Brigitte BACCAÏNI
Isabelle BENSIDOUN
Céline BESSIÈRE
Mara BISIGNANO
Delphine BROCHARD
Anne BORY
Valérie BOUSSARD
Thomas BRODATY
Marie-Christine BUREAU
Dominique CARDON
Vincent CARDON
Joanie CAYOUETTE-
REMBLIÈRE
Philippe COULANGEON
Pierre COURTIOUX
Martine D'AMOURS
Éric DELATTRE
Arnaud DUPRAY
Marc-Antoine ESTRADE

Gaëtan FLOCCO

Anne FRETEL

Charles GADEA

Carl GAIGNÉ

Jérôme GAUTIÉ

Marie GHIS MALFILATRE

Violaine GIRARD

Olivier GIRAUD

Olivier GODECHOT

Michel GROSSETTI

Mathilde GUERGOAT-

LARIVIÈRE

Mathieu HOCQUELET

Albert HONLONKOU

Arnaud HOUTE

Karen JAERHLING

Anne JOURDAIN

Lamia KANDIL

Julie LANDOUR

Sylvaine LAULOM

Julie LE GALLO

Marie-Hélène LECHIEN
Alexandre LÉNÉ

Marion MAISONOBE

Audrey MARIETTE

Bernard Cosmas MEKA'A

Ekaterina MELNIK-OLIVE

Stéphanie MOULLET

Cristina NIZZOLI

Vanessa di PAOLA

Jean-Marie PILLON

Lionel PROUTEAU

Emmanuel RAVALET

Thomas REVERDY

Muriel ROGER

Florent SARI

Gabrielle SCHÜTZ

Irène N. SELWANESS

Thomas SIGAUD

Laure de VERDALLE

Eric VERDIER

Nadège VÉZINAT

Marc-Antoine ZUNE 